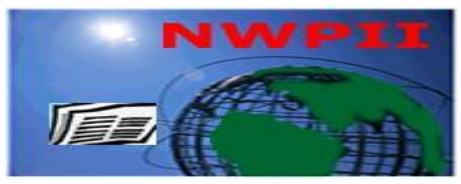

American Journal of Biomedical Sciences

ISSN: 1937-9080

nwpii.com/ajbms

\title{
pH-Switchable Electrochemical Interfaces-a Brief Review
}

\author{
Ying Tong, Bowen Gao, Hankun Yang, Lei Su and Xueji Zhang*
}

Research Center for Bioengineering and Sensing Technology, School of Chemistry and Biological Engineering, University of Science and Technology Beijing, Beijing, China.

"Corresponding Author

Prof. Xueji Zhang

Research Center for Bioengineering and Sensing Technology

School of Chemistry and Biological Engineering

University of Science and Technology Beijing

Beijing 100083, China.

E-mail: zhangxueji@ustb.edu.cn

Received: 16 February 2016; | Revised: 6 March 2016; | Accepted: 15 March 2016

\begin{abstract}
Recent advances in $\mathrm{pH}$-responsive materials have prompted the development of $\mathrm{pH}$-responsive electrochemical systems. Up to date, many types of electrochemical reactions have been incorporated into $\mathrm{pH}$-responsive electrochemical systems. The intelligent electrochemical interfaces have been widely used in many applications. The present review shows the recent progress in the combination of $\mathrm{pH}$-responsive materials, including inorganic, organic and biological materials, with various redox species for constructing the $\mathrm{pH}$-responsive electrochemical interfaces.
\end{abstract}

Keywords: $\mathrm{pH}$-responsive materials, $\mathrm{pH}$-responsive electrochemical interaces, polymers, carbon nanotubes.

\section{Introduction}

Stimuli-responsive materials, also known as "smart materials", can undergo reversible physical or chemical changes as a response to external stimuli, including biological stimuli (e.g. $\mathrm{Ph}$ [1] and glucose [2]) and externally applied triggers (e.g. temperature [3], light [4], magnetic field [5] and electric field [6]). They have shown great promise for a variety of applications including sensors, catalysis, drug delivery, and separations [7-10]. Among various external stimuli, $\mathrm{pH}$ is the most studied one. Recently, increasing interest has been devoted to the development of stimuli-responsive electrochemical composite materials due to that stimuli-responsive materials provide an opportunity to the controllable alternation of electrochemical reactions by using external stimuli. So far, many electrochemical reactions have been incorporated into stimuli-responsive systems, and the intelligent electrochemical interfaces have been widely used in many applications, including electrochemical sensors [11], electrocatalysis [1,12-13], and biofuel cells [14]. There are a number of reviews highlighting the development of responsive polymer-based electrochemical systems $[1,8,11,15-17]$. In this 
mini-review, we gives a short overview of the combination of $\mathrm{pH}$-sensitive inorganic, organic and biological materials with various redox species for constructing the $\mathrm{pH}$-responsive electrochemical interfaces.

\section{The combination of $\mathbf{p H}$-responsive polymers or hydrogels with redox species}

Among various stimuli-responsive materials, stimuli-responsive polymers or hydrogels are most studied. Stimuli-responsive polymers or hydrogels can respond to small alterations of certain environmental parameters with significant change in their volume. For instance, in alkaline solutions, hydrogels containing weak acidic groups are deprotonated. As a result, the density of the charged groups within the gel network strongly increases accompanied by an adequate generation of mobile counterions inside the gel, which induces the phase transition due to electrostatic repulsion. On the contrary, in acidic solutions, the weak acidic gels are protonated, leading to a decrease of both the charge density and the content of mobile counterions within the hydrogel. As a result, gels shrink [7]. The resulting changes in volume can be more than hundredfold. Many electrochemical reactions have been combined with $\mathrm{pH}$-sensitive polymers or hydrogels to form $\mathrm{pH}$-responsive electrochemical systems. In the following, we firstly introduce the redox species combined with $\mathrm{pH}$-responsive polymers or hydrogels, and the coupled biocatalytic reactions. Then, we show several approaches to alter the local $\mathrm{pH}$ change at electrode surfaces.

\subsection{Redox species incorporated with pH- responsive polymers or hydrogels}

\subsubsection{Ferricyanide hexaammineruthenium(III) chloride}

Negatively charged ferricyanide and positively charged hexaammineruthenium(III) chloride are the most utilized in the $\mathrm{pH}$ responsive electrochemical systems. For instance, Tam et al reported a pH-responsive mixed polyelectrolyte brush from tethered poly(acrylic acid) (PAA) and poly(2-vinylpyridine) (P2VP) [18]. The mixed brush demonstrated a bipolar permselective behavior, as shown in Figure 1. At $\mathrm{pH}<3$, the positively charged P2VP chains enabled the electrochemical process for $\left[\mathrm{Fe}(\mathrm{CN})_{6}\right]^{4-}$, while the redox process for $\left[\mathrm{Ru}\left(\mathrm{NH}_{3}\right)_{6}\right]^{3+}$ was effectively inhibited. On the contrary, at $\mathrm{pH}>6$, a reversible redox process for the positively charged redox probe, $\left[\mathrm{Ru}\left(\mathrm{NH}_{3}\right)_{6}\right]^{3+}$, was observed, while the redox process for the negatively charged redox species, $\left[\mathrm{Fe}(\mathrm{CN})_{6}\right]^{4-}$, was fully inhibited. a)

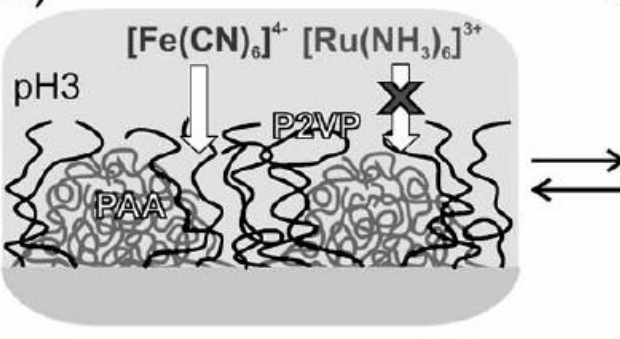

b)

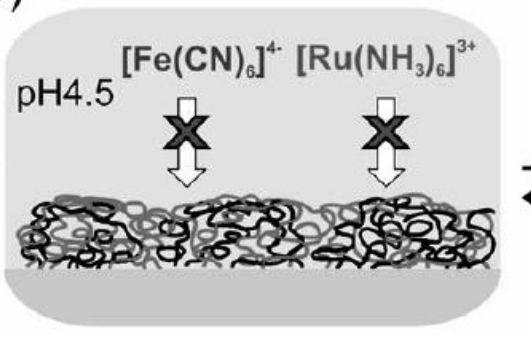

c)

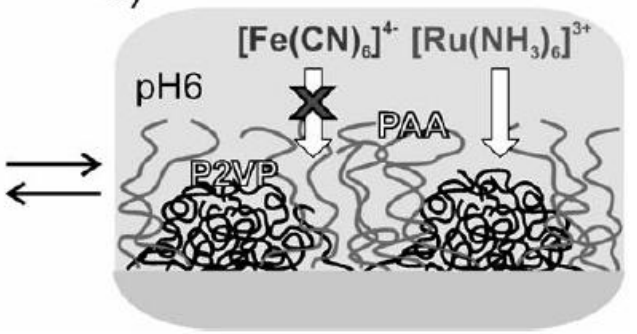

Figure 1. The polymer brush permeability for the differently charged redox probes controlled by the solution $\mathrm{pH}$ value: a) the positively charged protonated P2VP domains allow the electrode access for the negatively charged $\left[\mathrm{Fe}(\mathrm{CN})_{6}\right]^{4-}$; b) the neutral hydrophobic polymer thin-film inhibits the electrode access for all ionic species; c) the negatively charged dissociated PAA domains allow the electrode access for the positively charged $\left[\mathrm{Ru}\left(\mathrm{NH}_{3}\right)_{6}\right]^{3+}[18]$.

2.1.2 Soluble ferrocene derivatives

Am. J. Biomed. Sci. 2016, 8(1), 68-81; doi: 10.5099/aj160100068

(C) 2016 by NWPII. All rights reserved
$\mathrm{Hu}$ and co-workers reported a series of $\mathrm{pH}-$ responsive polymer modified electrode with 
ferrocenedicarboxylic acid $\left(\mathrm{Fc}(\mathrm{COOH})_{2}\right)$ as probe. For instance, poly(4-vinylpyridine) (P4VP) films were electropolymerized on a pyrolytic graphite (PG) electrode surface to control the electrochemistry of $\mathrm{Fc}(\mathrm{COOH})_{2}$ [19]. At the $\mathrm{P} 4 \mathrm{VP}$ films the cyclic voltammetric (CV) response of $\mathrm{Fc}(\mathrm{COOH})_{2}$ was observed to be very sensitive to the $\mathrm{pH}$. $\mathrm{Fc}(\mathrm{COOH})_{2}$ was at the "on" state with a relatively large $\mathrm{CV}$ oxidation peak current for the films at $\mathrm{pH} 4.0$ but showed the "off" state with significantly suppressed CV response at $\mathrm{pH}$ 7.0. In another study [20], weak polybase branched poly(ethyleneimine) (BPEI) and strong polyacid poly(styrenesulfonate) (PSS) were assembled into BPEI/ $\{\mathrm{PSS} / \mathrm{BPEI}\}$ n layerby-layer (LBL) films on electrodes by electrostatic interaction between them. The CV response of $\mathrm{Fc}(\mathrm{COOH})_{2}$ at $\mathrm{BPEI} /\{\mathrm{PSS} / \mathrm{BPEI}\} \mathrm{n}$ film electrodes was also observed to be very sensitive to the $\mathrm{pH}$ of the testing solutions. At $\mathrm{pH}$ 4.0, the probe showed a well-defined CV peak pair with relatively large peak currents for the films, while, at $\mathrm{pH} 7.0$, the $\mathrm{CV}$ response was significantly depressed. By switching the film electrodes in buffers between $\mathrm{pH} 4.0$ and 7.0, the $\mathrm{CV}$ peak currents changed periodically between a relatively high value at the "on" state and a very low value at the "off" state.

\subsubsection{Macrocyclic metal complexes}

Liu et al reported the fabrication of the chitosan- $\mathrm{Fe}\left(\right.$ notpH $\left._{3}\right)$ hybrids film by the simple one-step electrodeposition technique $\left(\mathrm{Fe}\left(\mathrm{notpH}_{3}\right)\right.$ : 1,4,7-triazacyclononane-1,4,7-triyl-tris

methylene-phosphonic acid iron(III) complex) [21]. $\mathrm{Fe}\left(\mathrm{notpH}_{3}\right)$ is a macrocyclic metal complex with three uncoordinated $-\mathrm{P}-\mathrm{OH}$ groups and a $\mathrm{pH}$-sensitive redox molecule. In their study, $\mathrm{Fe}\left(\operatorname{notpH}_{3}\right)$ complex was immobilized in chitosan polymer by means of the strong electrostatic and/or hydrogen bonding interactions between $\mathrm{Fe}\left(\operatorname{notpH}_{3}\right)$ and chitosan, which also enhances the insolubility of chitosan in acidic solution. The immobilized $\mathrm{Fe}\left(\right.$ notpH $\left._{3}\right)$ complex undergoes an effective direct electron transfer reaction and shows a particular $\mathrm{pH}$-sensitive electrochemical property.

Tam et al reported polymer brush-modified electrode with switchable and tunable redox activity for bioelectronic applications [22]. In their study, P4VP functionalized with Oscomplex redox units was grafted to an indium tin oxide (ITO) conductive support in the form of a polymer brush. At acidic $\mathrm{pH}$, the protonation of the pyridine units of the polymer backbone resulted in the swelling of the polymer brush allowing quasi-diffusional translocation of the flexible polymer chains, thus providing direct contact of the polymer-bound Os-complex redox units and the conducting electrode support. At the neutral $\mathrm{pH}$, the uncharged polymer formed values existed in the shrunk state, when the mobility of the polymer chains was restricted and the polymer-bound Os-complex redox units were not electrically accessible from the conducting support, thus resulting in the nonactive state of the modified electrode.

\subsubsection{Redox-active dyes}

Willner and co-workers reported the $\mathrm{pH}$ stimulated formation and dissociation of boronate ester complexes between redox lablefunctionalized AuNPs and electrodes [13]. In their study, the AuNPs functionalized with a mixed monolayer consisting of redox-active electron transfer units (e.g. methylene blue $\left(\mathrm{MB}^{+}\right)$), and a ligand capable of generating the boronate ester linkages (e.g., boronic acid or dithiothreitol), provide a bifunctional capping layer that allows the reversible binding/dissociation of the NPs to, and from, the electrode.

\subsubsection{Redox proteins}

Among various redox proteins, cytochrome c (Cyt c) is an important heme-containing metalloprotein, which is bound to the mitochondrial membrane and functions as an electron carrier in the respiratory chain. Li and co-workers reported a pH-sensitive polymerbrush interface prepared by electrochemically induced polymerization of acrylic acid to control the electrochemistry of Cyt c [23]. At the PAA brush-modified conductive substrates, the reversible immobilization and direct electron transfer process of Cyt c could be effectively controlled by the environmental $\mathrm{pH}$. Recently, Zhang and co-workers reported fabrication of a 
light or $\mathrm{pH}$ dual-responsive reactivated biocompatible interface using the photocontrolled reversible host-guest interaction between photoresponsive azobenzene-containing self-assembled monolayer (SAM) and the $\mathrm{pH}$-responsive PAA polymer grafted with cyclodextrin moieties [24]. In another study, Zhang and co-workers reported fabrication of a biosurface for nearly complete and reversible resistance of Cyt $\mathrm{c}$ using an inclusion reaction between an azobenzenecontaining self-assembled monolayer and $\mathrm{pH}$-responsive poly(ethylene glycol)-block-
PAA grafted with cyclodextrins (PEG-PAA-gCD) [25]. In these cases, the pH-responsive layers at electrodes are formed with PAA, because PAA is not only a $\mathrm{pH}$-responsive biocompatible polymer, also is an excellent adsorption matrix to effectively anchor Cyt c onto surfaces, and a good accelerant for the direct electron transfer of Cyt c. The $\mathrm{pH}$-responsive interface can be switched between an extended state and a relaxed state for the reversible resistance of Cyt c adsorption completely in cooperation with protein-resistant PEG.
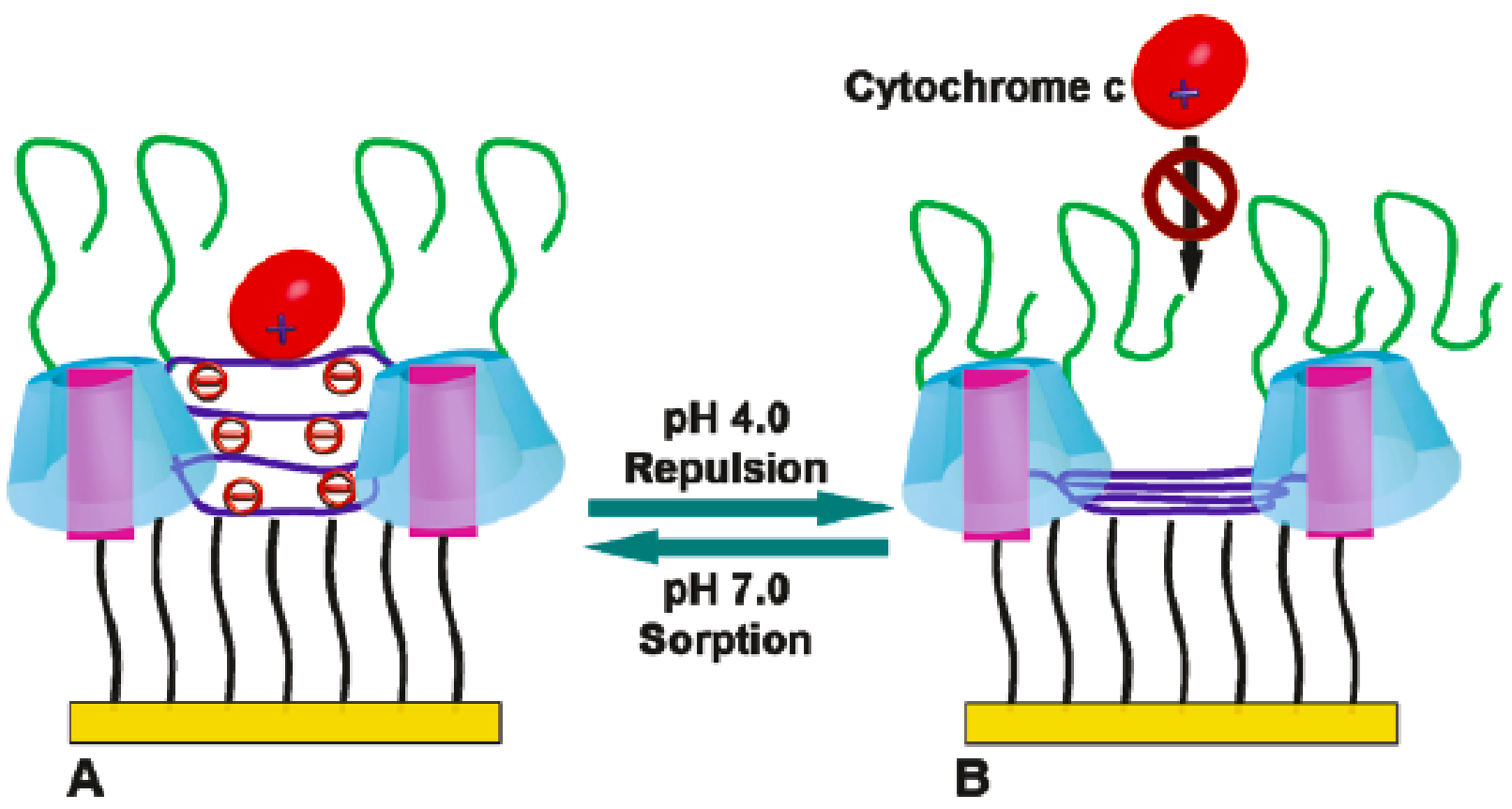

Figure 2. pH-Responsive switching of the PEG-PAA-g-CD-Protecting biointerface containing protein-resistant PEG between the stretched state at $\mathrm{pH} 7.0$ to immobilize Cyt $\mathrm{c}(\mathrm{A})$ and the relaxed state at $\mathrm{pH} 4.0$ to resist Cyt $\mathrm{c}$ adsorption reversibly (B) [25].

\subsection{Enzymatic reactions incorporated into $\mathrm{pH}-$ responsive electrochemical systems}

\subsubsection{Ferricyanide-coupled enzymatic reactions}

Tiwari and co-workers reported $\mathrm{pH}$-induced on/off-switchable graphene bioelectronics [26]. In their study, the solution containing graphene oxide (GO)-GOD and P4VP was directly dropcast onto the glassy carbon (GC) electrode surface for forming $\mathrm{pH}$-sensitive electrochemical interfaces. With $\left[\mathrm{Fe}(\mathrm{CN})_{6}\right]^{3-/ 4-}$ as electron mediator, GOD-catalyzed glucose oxidation reaction proceeded and showed $\mathrm{pH}$-dependent current response. Recently, Huang and coworkers reported a glucose-responsive $\mathrm{pH}$ switchable bioelectrocatalytic sensor based on phenylboronic acid-diol specificity [27]. In their study, aminophenylboronic acid moieties were covalently grafted onto mercaptobenzoic acid moieties, and GOD was then immobilized through boronic acid-diol specific recognition to 
form a pH-sensitive electrosensor switching between $\mathrm{pH} 5.8$ and $\mathrm{pH} 8.0$ base solution. Using potassium ferricyanide as electroactive probe, the response was intensified in acidic condition while hindered in alkaline condition. In the presence of glucose, the response to glucose was further amplified catalytically by GOD on "ON" state, while electron transfer was inhibited on "OFF" state. In another study, Wang and co-workers reported $\mathrm{pH}$-switchable electrochemical sensing platform based on chitosan-reduced graphene oxide/concanavalin A layer [28]. The chitosanrGO/Con A with pH-dependent surface net charges exhibited $\mathrm{pH}$-switchable response to negatively charged $\mathrm{Fe}(\mathrm{CN})_{6}{ }^{3-}$.

\subsubsection{Ferrocenedicarboxylic acid-coupled enzymatic reactions}

$\mathrm{Hu}$ and co-workers reported the LBL assembly of oppositely charged poly(allylamine hydrochloride) (PAH) and hyaluronic acid (HA) on PG electrodes, followed by immobilization of GOD [29]. Due to the presence of GOD, the redox process of $\mathrm{Fc}(\mathrm{COOH})_{2}$ at $\mathrm{pH}$-sensitive PAH/HA film-modified electrode can be coupled with the bioelectrocatalysis of GOD toward glucose oxidation. The bioelectrocatalysis for the film system was at the "on" state at $\mathrm{pH} 5.0$ and at the "off" state at $\mathrm{pH}$ 9.0. In another study [30], they reported $\mathrm{pH}$-switchable bioelectrocatalysis based on LBL films assembled with GOD and BPEI. GOD were directly assembled with BPEI into $\{\mathrm{BPEI} / \mathrm{GOD}\}_{\mathrm{n}} \mathrm{LBL}$ films on the surface of electrodes mainly by electrostatic interaction between them. The $\mathrm{CV}$ response of $\mathrm{Fc}(\mathrm{COOH})_{2}$ at $\{\mathrm{BPEI} / \mathrm{GOD}\} \mathrm{n}$ film electrodes was very sensitive to the environmental $\mathrm{pH}$. The $\mathrm{CV}$ peak currents of $\mathrm{Fc}(\mathrm{COOH})_{2}$ were quite large at $\mathrm{pH} 4.0$ but greatly suppressed at $\mathrm{pH} 7.0$, demonstrating reversible $\mathrm{pH}$-sensitive on-off behavior. The observed $\mathrm{pH}$-switchable $\mathrm{CV}$ response could be attributed to the fact that the electrostatic interaction between the films and the probe plays a key role in deciding the $\mathrm{pH}$-sensitive on-off behavior of the system. This smart interface could be used to realize $\mathrm{pH}$-switchable electrocatalytic oxidation of glucose by GOD in the films and mediated by $\mathrm{Fc}(\mathrm{COOH})_{2}$ in solution. Pedrosa and co-workers reported the utilization of $\mathrm{pH}$-sensitive polymer brushes incorporated with NPs and GODs for fabricating $\mathrm{pH}$-switchable biosensors [31]. In their study, P2VP brushes were formed on an ITO electrode using the "grafting-to" method. Then, citrate ionstabilized AuNPs were adsorbed onto the polymer brush. To attach GOD, the AuNPcovered electrodes were treated with a methanol solution of 11-mercaptoundecanoic acid (MUA), followed by attachment of GOD using the standard N-hydroxysuccinimide (NHS)/N-ethylN'-(3-dimethylaminopropyl) carbodiimide (EDC) conjugation chemistry. The fabricated GOD/P2VP/AuNP modified electrode also exhibited $\mathrm{pH}$-switchable oxidation current towards glucose in the presence of ferrocene.

\subsubsection{Os complexes-coupled enzymatic reactions}

Tam et al reported polymer brush-modified electrode with switchable and tunable redox activity for bioelectronic applications [22]. In their study, P4VP functionalized with Oscomplex redox units was grafted to an ITO conductive support in the form of a polymer brush. The primary electrochemical activity of the Os-modified electrode was coupled with a biocatalytic oxidation of glucose in the presence of soluble GOD, thus allowing reversible activation of the bioelectrocatalytic process. In another study, Contin et al reported the hydrogel film of aldehyde oxidoreductase (PaoABC) entrapped within the $\left[\mathrm{Os}(\mathrm{bpy})_{2} \mathrm{Cl}\right]^{+}-$modified polyvinyl imidazole [32]. The poly(vinyl)imidazole $\mathrm{Os}(\mathrm{bpy})_{2} \mathrm{Cl}$ hydrogel displays $\mathrm{pH}$-responsive properties. PaoABC is a molybdenum-containing iron-sulfur flavoprotein located in bacterial periplasm. PaoABC was mixed with Os-complex modified poly(vinyl)imidazole and drop-coated on a GC electrode surface. In the presence of vanillin, a substrate of PaoABC, the highest catalytic currents for vanillin oxidation were observed at $\mathrm{pH} 4.5$, while at $\mathrm{pH}$ values above 6.5 the catalytic activity fully vanishes. The on-off transition is due to the electron transfer between the polymerbound Os-complexes and PaoABC which may depend either on electrostatic interactions or on the mobility of the Os-complexes in the hydrogel. 


\subsubsection{Redox-active dye-coupled enzymatic reactions}

Willner and co-workers reported $\mathrm{pH}$ switchable bioelectrocatalytic processes using AuNPs-modified electrodes [13]. In their study, the AuNPs functionalized with a mixed monolayer consisting of $\mathrm{MB}^{+}$, and a ligand capable of generating the boronate ester linkages (e.g., boronic acid or dithiothreitol), provide a bifunctional capping layer that allows the reversible binding/dissociation of the NPs to, and from, the electrode, thus leading to the mediated electron transfer between the horseradish peroxidase (HRP) and the electrode surface, resulting in the switchable bioelectrocatalyzed reduction of $\mathrm{H}_{2} \mathrm{O}_{2}$.

\subsection{Approaches to alter the local $\mathrm{pH}$ at electrode surface}

\subsubsection{Electrochemical reduction of oxygen}

The electrolysis of water produces hydrogen and oxygen gas, resulting in a change in solution
$\mathrm{pH}$ around the anode and cathode. Tam et al reported the use of the P4VP-brush-modified ITO electrode to switch reversibly the interfacial activity toward $\mathrm{Fe}(\mathrm{CN})_{6}{ }^{4-}$ by electroreduction of molecular oxygen [33]. In this way, the local $\mathrm{pH}$ at the electrode interface was changed to an alkaline $\mathrm{pH}$ value, due to the electrochemical reduction of $\mathrm{O}_{2}$ and the concomitant consumption of hydrogen ions at the electrode interface. The electrochemically produced local $\mathrm{pH}$ of 9.1 resulted in the deprotonation of the polymer brush. The produced hydrophobic shrunken state of the polymer brush was impermeable to $\mathrm{Fe}(\mathrm{CN})_{6}{ }^{4-}$, thus fully inhibiting its redox process at the electrode surface. The interface's return to the electrochemically active state was achieved by disconnecting the applied potential, followed by stirring the electrolyte solution or by slow diffusional exchange of the electrode-adjacent thin layer with the bulk solution.
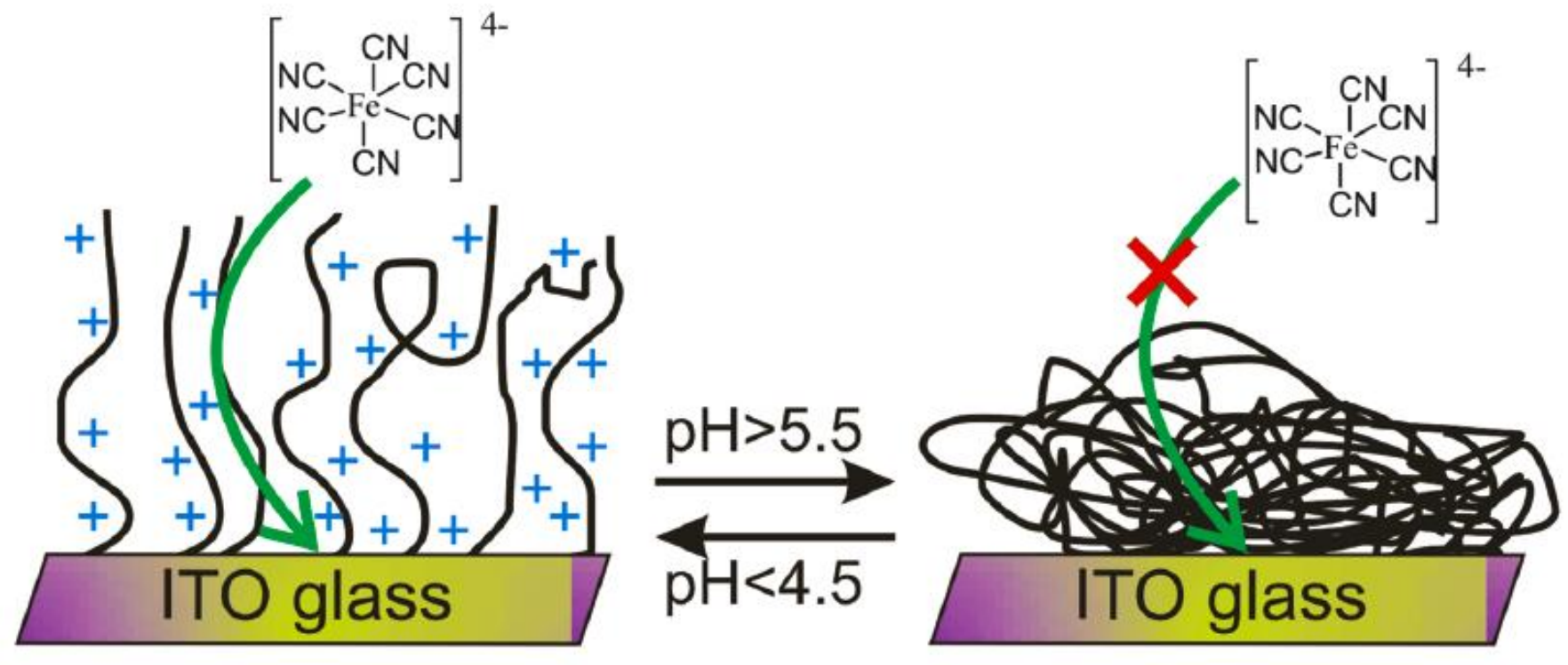

Figure 3. $\mathrm{pH}-$ Controlled reversible switching of the P4VP brush between the ON (left) and OFF (right) states allowing and restricting the anionic species' penetration to the electrode surface, thus activating and inhibiting the redox process [33].

\subsubsection{Enzymatic reaction}

Schuhmann and co-workers reported the modulation of electrostatic interactions between a
pH-responsive polymer and a redox enzyme to control the off-on transition for electrochemical signal generation [34]. In their study, GC 
electrodes are modified with a poly(vinyl)imidazole Os(bipyridine) ${ }_{2} \mathrm{Cl}$ redox hydrogel film entrapping urease and pyrroloquinoline quinone (PQQ)-dependent glucose dehydrogenase (GDH), while glucose is present in the solution. The off-on transition is based on the detection of urea which is hydrolyzed to ammonia by urease within the hydrogel film concomitantly increasing the local $\mathrm{pH}$ value thus invoking deprotonation of the

imidazole groups at the polymer backbone. The decrease of positive charges at the polymer decreases electrostatic repulsion between the polymer and the positively charged PQQdependent glucose dehydrogenase. Hence, electron transfer rates between polymer-bound Os complexes and PQQ inside the enzyme are enhanced activating electrocatalytic oxidation of glucose.
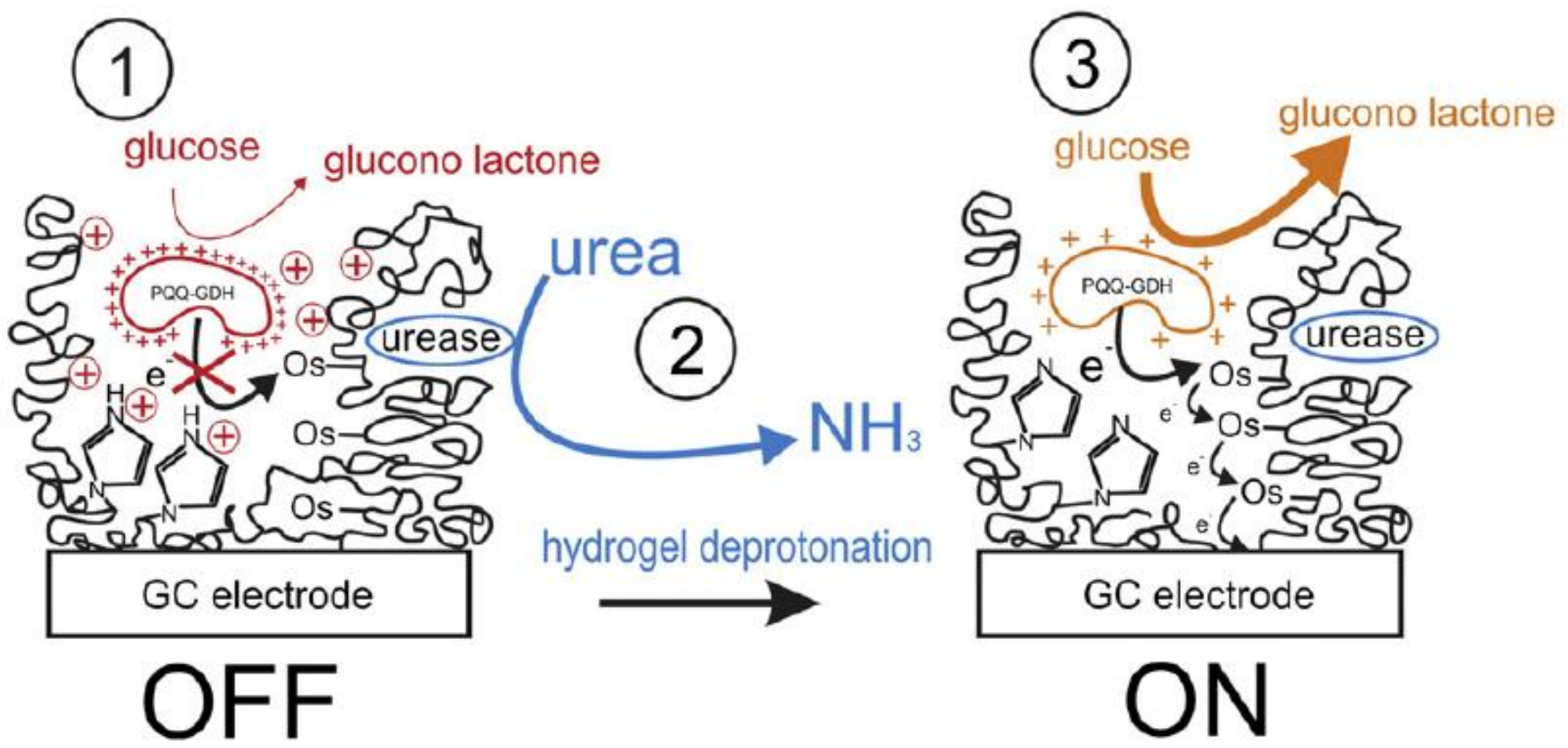

Figure 4. Schematic representation of the off-on transition regulated by the electrostatic interaction between the polymer backbone and PQQ-GDH. At acidic $\mathrm{pH}$ values, before the addition of urea (step 1), electrons coming fromglucose oxidation are not transferred via the polymer-bound Os complexes because of electrostatic repulsion between PQQ-GDH and polymer backbone. Upon the addition of urea (step 2), the deprotonation of the hydrogel results in amore favorable environment for the electric communication between the two elements, leading to a current signal due to glucose oxidation (step 3) [34].

In another study, Contin et al reported the utilization of esterase catalyzed ester hydrolysis to alter the local $\mathrm{pH}$ at electrode surface [32]. In that study, the esterase from porcine liver was coimmobilized within the $\mathrm{PaoABC} /\left[\mathrm{Os}(\mathrm{bpy})_{2} \mathrm{Cl}\right]+$ modified poly(vinyl imidazole) film. Methyl propionate which is hydrolyzed in the esterase catalyzed reaction under formation of propionic acid leading to a local acidification inside the polymer film.

\section{3. pH-Responsive electrochemical systems based on pH-responsive biomaterials}

\section{1 i-motif}

DNA has been demonstrated to be an extremely versatile building material for the assembly of novel nanostructures and nanodevices with unique functions [35-36]. Cytosine-rich (C-rich) nucleic acids, normally known as a kind of $\mathrm{pH}$-sensitive materials, appear in the human genome frequently, especially the 
telomere of human chromosomes. Under acidic conditions, a unique four-stranded nucleic acid secondary structure is formed, commonly known as i-motif. While in neutral or basic aqueous solution, i-motif is not stable and the strand adopts a random coil conformation [37].

\subsubsection{Ferricyanide combined with DNA}

Recently, Willner and co-workers reported controlling interfacial electron transfer and electrocatalysis by $\mathrm{pH}$-switchable DNA monolayer-modified electrodes [38]. The thiolated nucleic acid (1), which includes a cytosine-rich sequence that can form the i-motif, was immobilized on a Au electrode. At $\mathrm{pH} 7.0$, the system exists in the random coil configuration, whereas at $\mathrm{pH} 5.8$ the nucleic acid forms the imotif structure, a quadruplextype assembly in which $\mathrm{H}^{+}$bridges opposite cytosine units to form the structure. With $\mathrm{Fe}(\mathrm{CN})_{6}{ }^{3-14-}$ as a redox label, the electrode reveals a lower interfacial electron transfer resistance at $\mathrm{pH} 5.8$ than $\mathrm{pH}$ 7.0. Upon the cyclic application of electrolyte solutions at $\mathrm{pH} 5.8$ and $\mathrm{pH}$ 7.0, the interfacial electron transfer resistances at the electrode are reversibly switched between the lower and higher values, respectively.
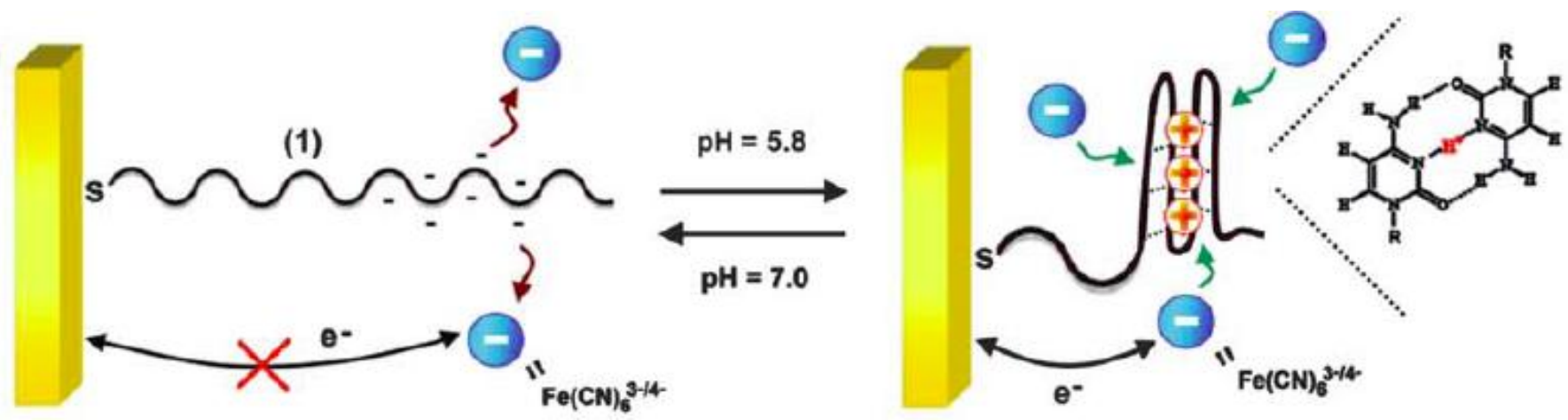

Figure 5. pH-switchable control of electron transfer on a nucleic acid, (1), monolayer-modified Au electrode through the reversible $\mathrm{pH}$-triggered formation and dissociation of an i-motif structure [38].

They also reported incorporation of a nucleic acid-modified electrode that undergoes $\mathrm{pH}$ induced random coil/i-motif transitions into the oscillatory $\mathrm{pH}$ system could lead to the autonomous cyclic control of the interfacial electron transfer resistances at the electrode surface [39]. While at $\mathrm{pH} 7.0$, the nucleic acid exists in a random coil configuration and at $\mathrm{pH}$ 5.0 the nucleic acid assembles into an i-motif structure. As a result, the periodic switching of the interfacial electron transfer resistances at the electrode surface between high and low values proceeds as the $\mathrm{pH}$ of the system oscillates between the values 7.0 and 5.0.

$\mathrm{Gao}$ et al reported a regenerated electrochemical biosensor for label-free detection of glucose and urea based on conformational switch of i-motif oligonucleotide probe. In their study, the GOD-catalyzed reaction is used to generate gluconic acid to provide proton to the solution and decrease the $\mathrm{pH}$ value, leading to the formation of i-motif structure. Therefore, the system presents $\mathrm{ON}$ state for $\mathrm{Fe}(\mathrm{CN})_{6}^{3-/ 4-}$ with a lower electron transfer resistance value because the hemi-protonated DNA skeleton is favorable for the interfacial electron transfer. On the other hand, the urease-catalyzed reaction is used to convert the solution $\mathrm{pH}$ to alkaline due to the generated ammonia. Thus, random coil conformation of DNA is recovered, switching OFF the interfacial electron transfer processes. A high electron transfer resistance can be observed due to the inaccessibility of the DNA for $\mathrm{Fe}(\mathrm{CN})_{6}^{3-/ 4-}$. Based on these enzyme-catalyzed reactions, the concentrations of glucose and urea can be quantitatively determined. 


\subsubsection{Ferrocene derivatives combined with DNA}

Recently, Shao and co-workers reported an iDNA based electrochemical $\mathrm{pH}$ sensor fabricated by attaching the ferrocene-labeled i-DNA (Fc-iDNA) onto a gold electrode [40]. The Fc-i-DNA is thiol terminated and can be bound to the gold electrode surface by Au-S interaction. With the variation of solution $\mathrm{pH}$, the distance between ferrocene moiety and electrode surface is changed, leading to different redox currents. Therefore, the measurement of the corresponding currents can be used to determine the $\mathrm{pH}$.

Till now, most reports about the i-motifbased electrochemical nanoswitches or biosensors utilize the intramolecular i-motif structures, while intermolecular structures are rare. Gao et al reported an i-Motif based $\mathrm{pH}$ induced electrochemical switches [42]. In their study, two C-rich DNA strands are employed to fabricate the intermolecular i-switch: strand 1 with thiol at the 5'-terminus immobilized on the gold electrode through the thiol-Au interaction, and Fc-labeled strand 2 that hybridizes with strand 1 to form an i-switch nanostructure. In neutral or basic aqueous solution, the i-switch is present in the form of an extended duplex that makes Fc far away from the electrode; a weak faradaic current is obtained, so-called "OFF" state. While in the slight acidic condition, an obvious signal is detected from $\mathrm{Fc}$ which approaches the electrode due to the formation of the i-motif, so-called "ON" state.

Besides ferricyanide and ferrocene derivatives, other redox probes such as violet [41] were also used to construct the i-motif-based electrochemical biosensors or switches.

\subsection{Proteins}

Recently, Gu and co-workers reported that $\mathrm{Hb}$, as an important redox respiratory protein in red cells, was coupled with metal NPs such as AuNPs [43] and AgNPs [44] to modify electrodes with remarkable response to different $\mathrm{pH}$ solution. For instance, the $\mathrm{pH}$ sensitive LBL films were fabricated by alternately adsorbing $\mathrm{Hb}$ and conductive AgNPs on the surface of chitosan modified GC electrode. The fabricated films showed excellent $\mathrm{pH}$-sensitive on-off properties toward the electroactive $\mathrm{Fe}(\mathrm{CN})_{6}{ }^{3-}$. The- $\mathrm{COOH}$ and $-\mathrm{NH}_{2}$ groups was considered to be critical for $\mathrm{pH}$-sensitive behavior of $\mathrm{Hb}$. The switching behavior is active "on" to the negatively charged probe $\left[\mathrm{Fe}(\mathrm{CN})_{6}{ }^{3-}\right]$ at $\mathrm{pH} 4.0$, but inactive "off" to the probe at $\mathrm{pH}$ 8.0. This switch can be applied for $\mathrm{pH}$-controlled reversible bioelectrocatalysis such as electroreduction of $\mathrm{H}_{2} \mathrm{O}_{2}$ catalyzed by $\mathrm{Hb}$. The same group also reported a similar $\mathrm{pH}$ switchable electrocatalytic-active film fabricated through LBL assembly of $\mathrm{Hb}$ and multiwall carbon nanotubes [45].

\section{4. pH-Responsive electrochemical systems based on pH-responsive inorganic materials}

Up to date, tremendous effort has been devoted to the fabrication of stimuli-responsive organic materials. However, the stimuliresponses brought about by active organic moieties are less durable. Thus, the development of versatile, durable, active materials is still one of central issues in materials science. Inorganic materials possess the relatively high chemical and physical durability. However, there have been very few reports of stimuli-responsive inorganic materials.

Carbon nanotubes (CNTs) are the typical one-dimensional inorganic nanocarbon materials that have had a profound impact on a wide range of applications. It has been known that the introduction of defects into CNTs or the doping of CNTs can be used to manipulate the electrical property of CNTs [46-48]. The carboxylation of CNTs can introduce the saturated $\mathrm{sp}^{3}$ carbon centers which act as scattering sites to alter the electronic and transport properties of the nanotubes and that the scattering strength of the $\mathrm{sp}^{3}$ carbon centers is associated with the local charge density [49]. Many groups have extensively investigated how the concentrations of hydrogen $\left(\mathrm{H}^{+}\right)$and hydroxyl $\left(\mathrm{OH}^{-}\right)$ions affect the electrical properties of CNTs [48,50-52]. In acidic solution, the carboxyl groups are protonated, resulting in a low local charge density and thus low scattering effect; at higher $\mathrm{pH}$, the carboxyl groups dissociate, resulting an increasing local charge density and thus increasing scattering effect. It has also been 
reported that the conductance of carboxylated CNTs decreases exponentially with the increase of $\mathrm{pH}$ due to the hole doping/undoping effects $[47,53]$. Such $\mathrm{pH}$-sensitive electrical property makes CNTs promising candidates for use as $\mathrm{pH}$ responsive materials. However, although CNTs have been extensively ulitized for development $\mathrm{pH}$ sensors especially in the form of ion-sensitive field effect transitor (ISFET), CNTs have received only limited attention as a kind of $\mathrm{pH}$ responsive material for the design of modified electrodes and only very few reports have been found.

Recently, Tong et al. reported fabrication of pH-responsive electrochemical MWCNT@ Prussian blue (PB) composite thin films by using carboxylated multi-walled carbon nanotubes (MWCNTs) [54]. LBL assembly method is used to deposit carboxylated MWCNTs multilayers onto an ITO conductive substrate, followed by chemical deposition of PB layer. The as-prepared MWCNT@PB composite films were found to change their electrochemical behaviors in response to the solution $\mathrm{pH}$, including their cyclic voltammetric and the corresponding electrochromic behaviors. The electrochromic state of PB could be switched on and off by the solution $\mathrm{pH}$. Electrochemical impedance spectroscopy (EIS) was performed to study the electrochemical behaviors of the MWCNT@PB composite film modified electrode The EIS results indicated that the changes in the solution $\mathrm{pH}$ affecting the protonation/deprotonation of the MWCNTs layer result in the changes in the charge transfer resistance at the MWCNTs|PB interface. The pH-responsive mechanism is depicted in Figure 6.

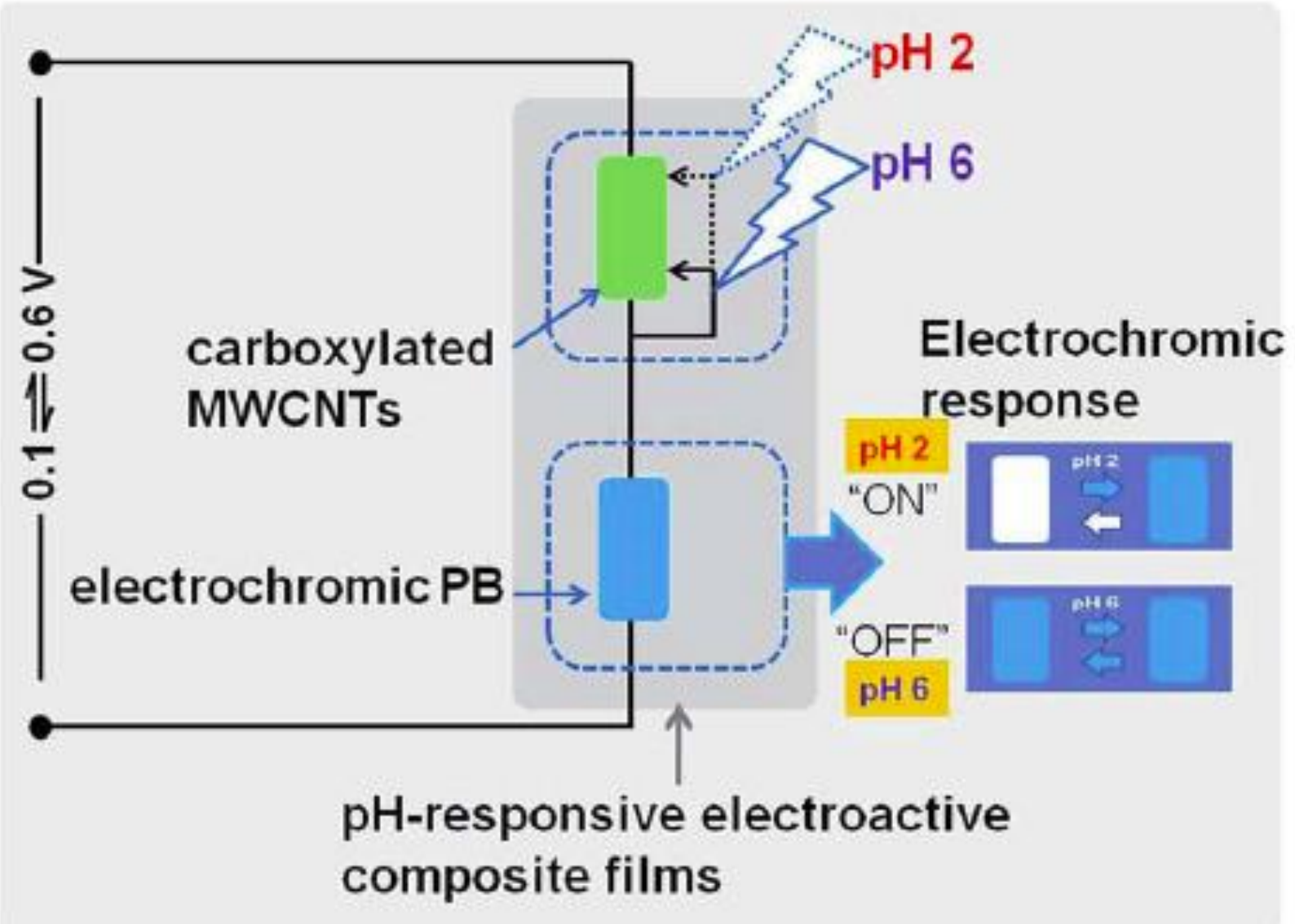

Figure 6. Schematic illustration of the pH-induced electrochemical responses of CMWCNT@PB composite films [54]. 
In another study, Ren et al. reported enhanced enzyme activity through electron transfer between single-walled carbon nanotubes and HRP [53]. In their study, HRP molecules were crosslinked onto carboxylated CNT with EDC as crosslinker. The carboxylated CNT participates in the electron transfer between HRP and the reducing substrate, and its excellent electron conductivity could accelerate the transportation of electrons, which leads to faster catalytic reaction. The enzyme activity enhancement should be closely related to the capability of CNT in accepting and conducting electrons. However, at the more basic pH, CNT was in a more reduced state with poorer capability to accept electron. Both the more reduced state and the decrease in conductance of carboxylated CNT could hold up the ET mediated by carboxylated CNT and thus result in smaller enzyme activity enhancement at basic $\mathrm{pH}$. Under extreme basic condition, carboxylated CNT even acted as an inhibitor probably by obstructing the substrate approaching the heme group.

\section{Summary and Outlook}

At the present state of development of the $\mathrm{pH}$-responsive electrochemical systems, which this paper reviews, the main issues facing $\mathrm{pH}$ responsive electrochemical systems are preparation of electrochemical systems and understanding of their $\mathrm{pH}$-responsive electrochemical performance. Although a number of applications have begun to appear, in general, this area is still very much in its infancy. Further efforts are needed to prompt the development of the $\mathrm{pH}$-responsive electrochemical systems. Up to date, a number of $\mathrm{pH}$-responsive polymer or hydrogels has been utilized to combine redox species for constructing $\mathrm{pH}$-switchable electrochemical systems. Compared with the $\mathrm{pH}-$ responsive electrochemical systems based on $\mathrm{pH}$ responsive organic materials, the $\mathrm{pH}$-responsive electrochemical systems based on $\mathrm{pH}$-responsive inorganic materials have been seldom reported. Therefore, further efforts are needed for developmeng of $\mathrm{pH}$-responsive inorganic materials and the combination of them with redox speices. On the other hand, although the basic concepts of the $\mathrm{pH}$-responsive electrochemical systems have been well demonstrated, the electrochemical reactions incorported in the $\mathrm{pH}$ responsive electrochemical systems are limited. More types of electrochemical reactions are needed to be utilized in this way to prompt the diversity of the $\mathrm{pH}$-responsive electrochemical systems.

\section{Acknowledgements}

The support from the National Natural Science Foundation of China (Grant No. 21175010, 21545012 and 21275017) and the grant from Beijing Municipal Science and Technology Commission (z131102002813058) is highly appreciated.

\section{References}

1. Katz, E.; Fernandez, V. M.; Pita, M. Switchable Bioelectrocatalysis Controlled by pH Changes. Electroanal. 2015; 27 (9): 20632073. DOI: 10.1002/elan.201500211

2. Huang, J.; Zhang, L.; Liang, R. P.; Qiu, J. D. "On-off” switchable electrochemical affinity nanobiosensor based on graphene oxide for ultrasensitive glucose sensing. Biosens. Bioelectron. 2013; 41 (15): 430-435. DOI: 10.1016/j.bios.2012.09.007

3. Fandrich, A.; Buller, J.; Schafer, D.; Wischerhoff, E.; Laschewsky, A.; Lisdat, F. Electrochemical characterization of a responsive macromolecular interface on gold. Phys. Status Solidi A 2015; 212 (6): 13591367. DOI: $10.1002 /$ pssa.201431698

4. Borges, J.; Rodrigues, L. C.; Reis, R. L.; Mano, J. F. Layer-by-Layer Assembly of Light-Responsive Polymeric Multilayer Systems. Adv. Funct. Mater. 2014; 24 (36): 5624-5648. DOI: 10.1002/adfm.201401050

5. Lim, C. S.; Ambrosi, A.; Sofer, Z.; Pumera, M. Magnetic control of electrochemical processes at electrode surface using iron-rich graphene materials with dual functionality. Nanoscale 2014; 6 (13): 7391-7396. DOI: 10.1039/C4NR01985G

6. Dunderdale, G. J.; Fairclough, J. P. A. Coupling $\mathrm{pH}-$ Responsive Polymer Brushes to 
Electricity: Switching Thickness and Creating Waves of Swelling or Collapse. Langmuir 2013; 29 (11): 3628-3635. DOI: $\underline{10.1021 / 1 \mathrm{a} 3049949}$

7. Richter, A.; Paschew, G.; Klatt, S.; Lienig, J.; Arndt, K. F.; Adler, H. J. P. Review on Hydrogel-based pH Sensors and Microsensors. Sensors-Basel 2008; 8 (1): 561-581. DOI:10.3390/s8010561

8. Parlak, O.; Turner, A. P. F. Switchable bioelectronics. Biosens. Bioelectron. 2016; 76: 251-265. DOI:10.1016/j.bios.2015.06.023

9. Lee, S. M.; Nguyen, S. T. Smart Nanoscale Drug Delivery Platforms from StimuliResponsive Polymers and Liposomes. Macromolecules 2013; 46 (23): 9169-9180. DOI: $10.1021 / \mathrm{ma} 401529 \mathrm{w}$

10. Ware, T.; Simon, D.; Rennaker, R. L.; Voit, W. mart Polymers for Neural Interfaces. Polym. Rev. 2013; 53 (1): 108-129. DOI:10.1080/15583724.2012.751924

11. Katz, E.; Minko, S.; Halamek, J.; MacVittie, K.; Yancey, K. Electrode interfaces switchable by physical and chemical signals for biosensing, biofuel, and biocomputing applications. Anal. Bioanal. Chem. 2013; 405 (11): 3659-3672. DOI:10.1007/s00216-0126525-2

12. Tam, T. K.; Zhou, J.; Pita, M.; Ornatska, M.; Minko, S.; Katz, E. Biochemically Controlled Bioelectrocatalytic Interface. J. Am. Chem. Soc. 2008; 130 (33): 10888-10889. DOI: 10.1021/ja8043882

13. Trifonov, A.; Yehezkeli, O.; Tel-Vered, R.; Willner, I. pH-Switchable Redox Reactions and Bioelectrocatalytic Processes Using Au Nanoparticles-Modified Electrodes. Electroanal. 2013; 25 (7): 1605-1612. DOI: 10.1002/elan.201300119

14. Katz, E.; Pita, M. Biofuel Cells Controlled by Logically Processed Biochemical Signals: Towards Physiologically Regulated Bioelectronic Devices. Chem.-Eur. J. 2009; 15 (46): 12554-12564. DOI: 10.1002/chem.200902367

15. Islam, M. R.; Lu, Z. Z.; Li, X.; Sarker, A. K.; Hu, L.; Choi, P.; Li, X.; Hakobyan, N.; Serpe, M. J. Responsive polymers for analytical applications: A review. Anal. Chim. Acta
2013; $\quad 789 \quad$ (30): $\quad$ 17-32.

DOI:10.1016/j.aca.2013.05.009

16. Wan, P. B.; Chen, X. D. Stimuli-Responsive Supramolecular Interfaces for Controllable Bioelectrocatalysis. Chemelectrochem 2014; 1 (10): 1602-1612. DOI: 10.1002/celc. 201402266

17. Peng, L.; Feng, A. C.; Huo, M.; Yuan, J. Y. Ferrocene-based supramolecular structures and their applications in electrochemical responsive systems. Chem Commun 2014; 50 (86): 13005-13014. DOI: 10.1039/C4CC05192K

18. Tam, T. K.; Pita, M.; Motornov, M.; Tokarev, I.; Minko, S.; Katz, E. Modified Electrodes with Switchable Selectivity for Cationic and Anionic Redox Species. Electroanal 2010; 22 (1) 35-40. DOI: 10.1002/elan.200900442

19. Song, S. L.; Hu, N. F. Dual-Switchable Bioelectrocatalysis Synergistically Controlled by $\mathrm{pH}$ and Perchlorate Concentration Based on Poly(4-vinylpyridine) Films. J Phys Chem B 2010; 114 (35): 11689-11695. DOI: 10.1021/jp105802m

20. Song, S. L.; Hu, N. F. pH-Controllable Bioelectrocatalysis Based on "On-Off" Switching Redox Property of Electroactive Probes for Spin-Assembled Layer-by-Layer Films Containing Branched Poly(ethyleneimine). J Phys Chem B 2010; 114 (10): 3648-3654. DOI: 10.1021/jp910048e

21. Liu, H. L.; Lu, D. K.; Li, P.; Chen, Y.; Zhou, Y. M.; Lu, T. H. One-step electrodeposition of chitosan/phosphonate iron(III) hybrids film and its pH-controlled switchable electrocatalytic behavior. J Electroanal Chem 2014; $717 \quad$ (15): 125-130. DOI:10.1016/j.jelechem.2014.01.003

22. Tam, T. K.; Ornatska, M.; Pita, M.; Minko, S.; Katz, E. Polymer Brush-Modified Electrode with Switchable and Tunable Redox Activity for Bioelectronic Applications. J Phys Chem C 2008; 112 (22): 8438-8445. DOI: 10.1021/jp801086w

23. Zhou, J. H.; Lu, X. B.; Hu, J. Q.; Li, J. H. Reversible Immobilization and Direct Electron Transfer of Cytochrome $\mathrm{c}$ on a $\mathrm{pH}-$ Sensitive Polymer Interface. Chem-Eur $J$ 
2007; 13 (10): 2847-2853. DOI: 10.1002/chem.200601335

24. Wan, P. B.; Wang, Y. P.; Jiang, Y. G.; Xu, H. P.; Zhang, X. Fabrication of Reactivated Biointerface for Dual-Controlled Reversible Immobilization of Cytochrome c. Adv. Mater. 2009; 21 (43): 4362-4365. DOI: 10.1002/adma.200901237

25. Wan, P. B.; Chen, Y. Y.; Xing, Y. B.; Chi, L. F.; Zhang, X. Combining Host-Guest Systems with Nonfouling Material for the Fabrication of a Biosurface: Toward Nearly Complete and Reversible Resistance of Cytochrome c Langmuir 2010; 26 (15): 12515-12517. DOI: 10.1021/la102336a

26. Parlak, O.; Turner, A. P. F.; Tiwari, A. pHinduced on/off-switchable graphene bioelectronics. J. Mater. Chem. B 2015; 3 (37): 7434-7439. DOI: 10.1039/C5TB01355K

27. Gao, P. Y.; Wang, Z. H.; Yang, L. L.; Ma, T. F.; Yang, L.; Guo, Q. Q.; Huang, S. S. A glucose-responsive $\quad \mathrm{pH}$-switchable bioelectrocatalytic sensor based on phenylboronic acid-diol specificity. Electrochim. Acta 2015; 151 (1): 370-377. DOI:10.1016/j.electacta.2014.11.054

28. Song, Y. H.; Liu, H. Y.; Tan, H. L.; Xu, F. G.; Jia, J. B.; Zhang, L. X.; Li, Z.; Wang, L. pH-Switchable Electrochemical Sensing Platform based on Chitosan-Reduced Graphene Oxide/Concanavalin A Layer for Assay of Glucose and Urea. Anal. Chem. 2014; 86 (4): 1980-1987. DOI: 10.1021/ac402742m

29. Liu, D.; Liu, H. Y.; Hu, N. F. pH-controllable bioelectrocatalysis of glucose by glucose oxidase loaded in weak polyelectrolyte layerby-layer films with ferrocene derivative as mediator. Electrochim. Acta 2010; 55 (1): 6426-6432.

DOI:10.1016/j.electacta.2010.06.042

30. Liu, D.; Hu, N. F. pH-switchable bioelectrocatalysis based on layer-by-layer films assembled with glucose oxidase and branched poly(ethyleneimine). Sensor. Actuat. B-Chem. 2011; 156 (2): 645-650. DOI:10.1016/j.snb.2011.02.011
31. Crulhas, B. P.; Sempionatto, J. R.; Cabral, M. F.; Minko, S.; Pedrosa, V. A. StimuliResponsive Biointerface Based on Polymer Brushes for Glucose Detection. Electroanal 2014; 26 (4): 815-822. DOI: 10.1002/elan.201400030

32. Contin, A.; Frasca, S.; Vivekananthan, J.; Leimkuhler, S.; Wollenberger, U.; Plumere, N.; Schuhmann, W. A pH Responsive Redox Hydrogel for Electrochemical Detection of Redox Silent Biocatalytic Processes. Control of Hydrogel Solvation. Electroanal 2015; 27 (4): 938-944. DOI: 10.1002/elan.201400621

33. Tam, T. K.; Pita, M.; Trotsenko, O.; Motornov, M.; Tokarev, I.; Halamek, J.; Minko, S.; Katz, E. Reversible "Closing" of an Electrode Interface Functionalized with a Polymer Brush by an Electrochemical Signal. Langmuir 2010; 26 (6): 4506-4513. DOI: $\underline{10.1021 / 1 a 903527 p}$

34. Contin, A.; Plumere, N.; Schuhmann, W. Controlling the charge of $\mathrm{pH}$-responsive redox hydrogels by means of redox-silent biocatalytic processes. A biocatalytic off/on switch. Electrochem Commun 2015; 51 : 5053. DOI:10.1016/j.elecom.2014.12.001

35. Wang, F.; Liu, X. Q.; Willner, I. DNA Switches: From Principles to Applications. Angew Chem Int Edit 2015; 54 (4): 10981129. DOI: $10.1002 /$ anie. 201404652

36. Liu, X. Q.; Lu, C. H.; Willner, I. Switchable Reconfiguration of Nucleic Acid Nanostructures by Stimuli-Responsive DNA Machines. Accounts Chem Res 2014; 47 (6): 1673-1680. DOI: 10.1021/ar400316h

37. Gao, Z. F.; Chen, D. M.; Lei, J. L.; Luo, H. Q.; Li, N. B. A regenerated electrochemical biosensor for label-free detection of glucose and urea based on conformational switch of imotif oligonucleotide probe. Anal Chim Acta 2015; $897 \quad$ (15): $\quad 10-16$. DOI:10.1016/j.aca.2015.09.045

38. Pelossof, G.; Tel-Vered, R.; Shimron, S.; Willner, I. Controlling interfacial electron transfer and electrocatalysis by $\mathrm{pH}$ - or ionswitchable DNA monolayer-modified electrodes. Chem Sci 2013; 4 (3): 1137-1144. DOI: $10.1039 / \mathrm{C} 2 \mathrm{SC} 22193 \mathrm{D}$ 
39. Qi, X. J.; Lu, C. H.; Liu, X. Q.; Shimron, S.; Yang, H. H.; Willner, I. Autonomous Control of Interfacial Electron Transfer and the Activation of DNA Machines by an Oscillatory pH System. Nano Lett. 2013; 13 (10): 4920-4924. DOI: 10.1021/n1402873y

40. Xu, X. D.; Li, B.; Xie, X. A.; Li, X. H.; Shen, L.; Shao, Y. H. An i-DNA based electrochemical sensor for proton detection. Talanta 2010; 82 (15): 1122-1125. DOI:10.1016/j.talanta.2010.06.019

41. Zhang, X. Y.; Luo, H. Q.; Li, N. B. Crystal violet as an i-motif structure probe for reversible and label-free $\mathrm{pH}$-driven electrochemical switch. Anal. Biochem. 2014; $455 \quad$ (15): 55-59. DOI:10.1016/j.ab.2014.03.015

42. Gao, X. Y.; Li, X. H.; Xiong, W. M.; Huang, H. M.; Lin, Z. Y.; Qiu, B.; Chen, G. N. iMotif based $\mathrm{pH}$ induced electrochemical switches. Electrochem. Commun. 2012; 24 : 9-12. DOI:10.1016/j.elecom.2012.06.039

43. Liu, Y.; Shi, L.; Gong, J.; Fang, Y. T.; Bao, N.; Gu, H. Y.; Zeng, J. Glassy carbon electrode modified with gold nanoparticles and hemoglobin in a chitosan matrix for improved $\mathrm{pH}$-switchable sensing of hydrogen peroxide. Microchim. Acta 2015; 182 (15): 2461-2468. DOI:10.1007/s00604-015-1597-2

44. Yu, C. M.; Ji, W. Y.; Gou, L. L.; Bao, N.; Gu, H. Y. The pH-sensitive switchable behavior based on the layer-by-layer films of hemoglobin and Ag nanoparticles. Electrochem. Commun. 2011; 13 (12): 15021503. DOI:10.1016/j.elecom.2011.10.012

45. Pan, Z. Q.; Liu, X. J.; Xie, J.; Sao, N.; He, H.; Li, X. D.; Zeng, J.; Gu, H. Y. Layer by layer assembled films between hemoglobin and multiwall carbon nanotubes for $\mathrm{pH}$ switchable biosensing. Colloid. Surface B 2015; $\quad 129 \quad$ (1): $\quad 169-174$. DOI:10.1016/j.colsurfb.2015.03.044

46. Back, J. H.; Shim, M. pH-Dependent Electron-Transport Properties of Carbon Nanotubes. J. Phys. Chem. B 2006; 110 (47): 23736-23741. DOI: 10.1021/jp063260x
47. Lee, D.; Cui, T. H. pHpH-dependent conductance behaviors of layer-by-layer selfassembled carboxylated carbon nanotube multilayer thin-film sensors. J. Vac. Sci. $\begin{array}{lllll}\text { Technol. } \quad B \quad 2009 ; & 27 & \text { (2): } 842 .\end{array}$ DOI:10.1116/1.3002386

48. Lee, D.; Cui, T. J. Layer-by-Layer SelfAssembly of Single-Walled Carbon Nanotubes with Amine-Functionalized Weak Polyelectrolytes for Electrochemically Tunable pH Sensitivity. Langmuir 2011; 27 (7): 3348-3354. DOI: 10.1021/la1047547

49. Park, H.; Zhao, J. J.; Lu, J. P. Effects of Sidewall Functionalization on Conducting Properties of Single Wall Carbon Nanotubes. Nano Lett. 2006; 6 (5): 916-919. DOI: 10.1021/n1052488d

50. Gou, P. P.; Kraut, N. D.; Feigel, I. M.; Bai, H.; Morgan, G. J.; Chen, Y. A.; Tang, Y. F.; Bocan, K.; Stachel, J.; Berger, L.; Mickle, M.; Sejdic, E.; Star, A. Carbon Nanotube Chemiresistor for Wireless $\mathrm{pH}$ Sensing. Sci. Rep. 2014; 4. DOI:10.1038/srep04468

51. Jung, D.; Han, M. E.; Lee, G. S. pH-sensing characteristics of multi-walled carbon nanotube sheet. Mater. Lett. 2014; 116 (1): 57-60. DOI:10.1016/j.matlet.2013.10.095

52. Maroto, A.; Balasubramanian, K.; Burghard, M.; Kern, K. Functionalized Metallic Carbon Nanotube Devices for $\mathrm{pH}$ Sensing. Chemphyschem 2007; 8 (2): 220-223. DOI: 10.1002/cphc.200600498

53. Ren, L.; Yan, D.; Zhong, W. W. Enhanced enzyme activity through electron transfer between single-walled carbon nanotubes and horseradish peroxidase. Carbon 2012; 50 (3): 1303-1310. DOI:10.1016/j.carbon.2011.10.053

54. Tong, Y.; Wang, Y. Y.; Gao, B. W.; Su, L.; Zhang, X. J. pH-Switchable electroactive composite films of carboxylated multi-walled carbon nanotubes and Prussian blue. Rsc $A d v$. 2015; 5 (125): 103184-103188. DOI: $\underline{10.1039 / \mathrm{C} 5 \mathrm{RA} 21751 \mathrm{~B}}$ 